\title{
Managing Depression with Bupleurum chinense Herbal Formula: A Systematic Review and Meta-Analysis of Randomized Controlled Trials
}

\author{
Lingling Yang, MD, Johannah L. Shergis, $\mathrm{PhD}_{1}^{2}$ Yuan M. Di, $\mathrm{PhD}_{1}^{2}$ \\ Anthony L. Zhang, PhD, ${ }^{2}$ Chuanjian Lu, PhD, Xinfeng Guo, PhD, \\ Zenan Fang, MD, Charlie Changli Xue, $\mathrm{PhD}^{1,2}$ and Yan $\mathrm{Li}^{1} \mathrm{PhD}^{1}$
}

\begin{abstract}
Objectives: Bupleurum chinense (BC; Radix Bupleuri) formulae are widely used in herbal medicine clinical practice for major depressive disorder (MDD). This study provides an up-to-date and comprehensive systematic review and meta-analysis of BC formula for MDD.

Design: Randomized controlled trials were retrieved from English and Chinese databases, from their inceptions to March 2019. Included studies compared BC formula alone or as integrative medicine to selective serotonin reuptake inhibitor (SSRI) antidepressants. Studies included adults 18-65 years of age. People with other types of depression or physical comorbidities, such as poststroke depression, bipolar, and other mental or physical disorders, were excluded. Meta-analysis was performed using STATA software. Grading of Recommendations Assessment, Development, and Evaluation was also conducted to assess the quality of evidence.

Results: Thirty studies compared BC formula to antidepressants and 25 studies compared BC formula plus antidepressants to antidepressants alone. BC formula was more effective than antidepressants at improving depression severity measured on the Hamilton Rating Scale for Depression (HRSD) (standardized mean difference [SMD] $-0.35,95 \%$ confidence interval $[\mathrm{CI}]-0.52$ to $-0.18, I^{2}=81.2 \%$ ). Integrative use of $\mathrm{BC}$ formula plus SSRIs was also superior to SSRIs alone at improving HRSD scores (SMD -1.03, 95\% CI -1.43 to $-0.62, I^{2}=94.2 \%$ ). However, heterogeneity of the included studies was high and quality was low. The total number and severity of adverse events in the BC formula groups were less than that in the antidepressant groups.

Conclusions: BC formula alone or given as integrative medicine with antidepressants reduced depression severity. However, the evidence is low quality and at risk of bias. Well-designed studies are needed to validate the results we identified in this review.
\end{abstract}

Keywords: major depressive disorder, Bupleurum chinense, herbal medicine, systematic review, meta-analysis, randomized controlled trial

\footnotetext{
${ }^{1}$ Guangdong Provincial Hospital of Traditional Chinese Medicine, Guangdong Provincial Academy of Chinese Medical Sciences, and The Second Clinical College, Guangzhou University of Chinese Medicine, Guangzhou, P.R. China.

${ }^{2}$ The China-Australia International Research Centre for Chinese Medicine, School of Health and Biomedical Sciences, RMIT University, Bundoora, Australia.
} 


\section{Introduction}

$\mathbf{M}$ AJOR DEPRESSIVE DISORDER (MDD), commonly referred to as depression, unipolar depression, or clinical depression, is one of the most common mood disorders affecting individuals and societies worldwide. ${ }^{1,2}$ It is associated with significant disability and mortality, and accounts for more than $40 \%$ of all mental disorders and substance abuse disorders. ${ }^{3}$ It is characterized by sadness, loss of interest, and decreased energy, as well as other symptoms, including reduced self-esteem, loss of confidence, inappropriate or excessive guilt, and thoughts of death or suicide. ${ }^{4}$

Depression is increasing in prevalence ${ }^{5}$ and is predicted to be the second most common burden of disease by $2020 .^{6}$ The Global Burden of Disease Study reported that the disability-adjusted life years for MDD ranked 15th in 1990 and 11 th in $2010 .^{7}$ It is estimated that as many as $12 \%$ of the population, both in developed and developing countries, will experience depression in their lifetime. ${ }^{8}$

In primary care practice, people with depression are commonly prescribed antidepressants, such as selective serotonin reuptake inhibitors (SSRIs). ${ }^{9,10}$ However, these treatments often need to be maintained even after remission and patients can become noncompliant when using antidepressants. $^{1,11-13}$ Noncompliance is sometimes due to adverse events, such as dry mouth, dizziness, gastrointestinal effects, sexual dysfunction, sedation, and weight gain. ${ }^{14-17}$ Discontinuing medication and noncompliance have been reported to be associated with increased risk of recurrence of depression and high medical costs. ${ }^{18,19}$

People with depression often use herbal medicine to alleviate symptoms or to avoid adverse events caused by antidepressants. In addition, they often believe herbal medicines are safe. ${ }^{20,21}$ Research also indicates depression is an indicator and predictor of herbal medicine use. ${ }^{22,23}$ However, there is a lack of evidence showing a statistically significant benefit or reduction in harms of herbal medicine compared to antidepressants. $^{24,25}$

Research has revealed a variety of chemicals, pharmacological agents, and clinical benefits of herbs for depression. $^{26,27}$ Bupleurum chinense DC (termed BC in this article) [Radix Bupleuri; Family: Apiaceae; Chinese name: Chai hu] is one of the most important herbs in Chinese medicine for depression and has been widely used in Asia and increasingly used in Western countries. Approximately, 74 compounds have been isolated from BC, including essential oils, triterpenoid saponins, polyacetylenes, flavonoids, lignans, fatty acids, and sterols. ${ }^{28} \mathrm{BC}$ is commonly combined with other herbal ingredients to make a formula (e.g., BC is combined with Citrus reticulata, Ligusticum chuanxiong, Citrus aurantium, Paeonia lactiflora, Glycyrrhiza spp., and Cyperus rotundus to make Chai hu shu gan san; or with Angelica sinensis, P. lactiflora, Atractylodes macrocephala, Poria cocos, Glycyrrhiza spp., Mentha haplocalyx, and Zingiber officinale to make Xiao yao san).

Previous systematic reviews of randomized controlled trials (RCTs) of BC formula, including Chai hu shu gan san and Xiao yao san, indicate that $\mathrm{BC}$ formula may be effective for depression, subclinical depression, including dysthymia, and secondary depression, such as poststroke depression. ${ }^{29,30}$ However, the results from previous reviews were limited by poor quality studies. This systematic review provides an updated and focused assessment and analysis of the effecacy and safety of all types of BC formula for MDD compared to SSRI antidepressants.

\section{Methods}

We followed the methods described in the Cochrane Handbook of Systematic Reviews. ${ }^{31}$

\section{Inclusion and exclusion criteria}

This review is a part of a larger project initiated by the China-Australia International Research Centre for Chinese Medicine and a systematic review protocol is registered with PROSPERO (CRD42018091770). The inclusion and exclusion criteria were predefined by the review team before data extraction.

Participants. Included studies were prospective, parallel RCTs, with participants 18-65 years of age and diagnosed with depression based on established clinical guidelines, including the Diagnostic and Statistical Manual of Mental Disorders (DSM), ${ }^{4}$ the Chinese Classification of Mental Disorders (CCMD-3), ${ }^{32}$ and the International Classification of Diseases (ICD-10). ${ }^{33}$ We excluded studies that included participants with other types of depression, such as bipolar disorder, dysthymia, depressive symptoms caused by other mental or physical disorders, or depression caused by another medical condition or a substance.

Interventions and comparators. We included studies that used oral BC formula alone or in combination with other herbs as the intervention. We chose SSRIs as the comparator in this review, because clinical guidelines recommend SSRIs to treat depression. ${ }^{16,34,35} \mathrm{We}$ excluded studies that did not specify the type of antidepressants used as comparator.

Outcomes. Prespecified outcomes included clinicianrated scales, such as the Hamilton Rating Scale for Depression (HRSD), ${ }^{36}$ and self-rated scales, such as the Zung's Self-Rating Depression Scale (SDS) ${ }^{37}$ and the MontgomeryAsberg Depression Rating Scale. ${ }^{38}$ These scales measure depression severity and related symptoms. Other outcomes included number of participants who relapsed or achieved remission, quality of life, functional capacity (e.g., social adjustment scales), suicidality, and adverse events.

\section{Search strategy}

We searched English and Chinese databases from their inceptions to March 2019. English databases included PubMed, Excerpta Medica Database (Embase), Cumulative Index of Nursing and Allied Health Literature (CINAHL), Cochrane Central Register of Comparatorled Trials (CENTRAL), and Allied and Complementary Medicine Database (AMED). Chinese databases included China BioMedical Literature (CBM), China National Knowledge Infrastructure (CNKI), Chongqing VIP (CQVIP), and Wanfang.

Search terms were mapped to controlled vocabulary in three groups: (1) condition (depression, depressive disorder, unipolar depression, major depression, major depressive disorder, and related terms); (2) intervention type (Chinese herbal medicine, herbal medicine, Bupleurum chinense, and 
related terms); and (3) study design (randomized controlled trials and related terms) (Supplementary Table S1).

In addition to electronic databases, we searched the reference lists of previous systematic reviews and their included studies. We also searched clinical trial registries for completed studies, including the United States National Institutes of Health register (ClinicalTrials.gov), the Chinese Clinical Trial Registry (ChiCTR), the European Union Clinical Trials Register (EU-CTR), and the Australian New Zealand Clinical Trials Registry (ANZCTR).

\section{Data extraction}

Search results from the English and Chinese databases were merged and duplicates were removed. Three reviewers (L.Y., J.L.S., and Y.M.D.) screened titles and abstracts and disagreements were resolved by discussion with a fourth reviewer (A.L.Z.). Full texts were obtained and screened against the inclusion criteria. Two reviewers (L.Y. and Y.M.D.) independently extracted data from relevant studies in EpiData software (EpiData Association, Odense, Denmark). Data checking and disagreements were resolved by discussion with a third reviewer J.L.S. Data included author names, publication year, title, journal, location, study design, diagnostic criteria, age, gender, intervention, comparator, outcome measures, treatment duration, sample size, dropouts, and adverse events.

\section{Risk of bias}

Two reviewers (L.Y. and Y.M.D.) independently used the risk of bias assessment tool from the Cochrane Handbook to assess risk of bias for each publication. ${ }^{31} \mathrm{~A}$ third reviewer (J.L.S.) resolved any disagreement about risk of bias. Potential publication bias was assessed using Funnel plots and Egger's test.

\section{Data analysis}

Studies were synthesized using meta-analysis. Continuous outcome data were analyzed using mean difference (MD) and $95 \%$ confidence intervals (CIs). When different versions of outcome measures were used, standardized mean difference (SMD) was used for data analysis. Statistical heterogeneity was assessed using the $I^{2}$ statistic. An $I^{2}$ over $50 \%$ was considered to be an indicator of substantial heterogeneity. ${ }^{31}$ Subgroup analyses were planned based on participant characteristics and study design, such as treatment duration, low risk of bias for sequence generation, and different versions of outcome measures.

\section{Results}

\section{Characteristics of the included studies}

Database searches identified 30,733 citations. After removing duplicates and excluding ineligible studies, we included a total of 55 RCTs (Fig. 1). ${ }^{39-93}$ Thirty of these RCTs $(54.5 \%)$ compared BC formula to SSRIs, and 25 RCTs (45.5\%) compared BC formula plus SSRIs to SSRIs alone (Table 1). All clinical studies were conducted in China and published from 2006 to 2017. Studies enrolled 5572 participants (sample size range: 46-480). Participants' ages ranged from 18 to 65 years. The duration of depression ranged from 1 month to 15 years, including single and recurrent episodes. Treatment duration ranged from 2 to 12 weeks (Table 1).

All BC formula treatments were orally administered by the following herbal preparations: decoctions, oral solutions, capsules, granules, pills, and tablets. The studies used $49 \mathrm{BC}$ formula and 103 different herbs. The most common formulae (including their modified forms) were Xiao yao san/ wan (12 studies, 21.8\%), Chai hu shu gan san (5 studies, $9.0 \%$ ), Suan zao ren tang (2 studies, 3.6\%), and Bu shen shu gan hua yu tang (2 studies, 3.6\%) (Table 1).

The studies included the following SSRIs: fluoxetine (29 studies, $52.7 \%$ ), paroxetine (16 studies, $29.1 \%$ ), sertraline (7 studies, $12.7 \%$ ), citalopram (2 studies, $3.6 \%$ ), and escitalopram (1 study, 1.8\%). All comparators were fixed dose and recommended by current clinical guidelines. ${ }^{16,34,94}$

In terms of outcome measures, depression symptoms were commonly assessed using the HRSD (54 studies, 98.2\%) and SDS (7 studies, 12.7\%). Quality of life was assessed using the Short Form 36-Item Health Survey (SF$36)$ in one study $(1.8 \%)$. Relapse and remission of depression, functional capacity, and suicidality were not assessed in the included studies. Adverse events were reported in 22 studies (40\%). All events were considered mild (Table 4).

\section{Risk of bias}

All studies were described as randomized; however, only $14(25.5 \%)$ described an appropriate method of random sequence generation and were judged at low risk of bias. Two (3.6\%) described an appropriate method of allocation concealment, while $53(96.4 \%)$ did not describe the details of allocation concealment, so were judged as having unclear risk of bias. Blinding of participants and personnel was reported in six studies $(10.9 \%)$; these were judged to be at low risk of bias, while the remaining 49 studies $(89.1 \%)$ were judged at high risk of bias. The method of blinding of outcome assessors was judged at low risk of bias in eight studies $(14.5 \%)$. Outcome data were available for most studies, with $54(98.1 \%)$ judged at low risk of bias. Selective outcome reporting was judged at unclear risk in all the studies because protocols were not available. Risk of bias assessment for each study is included in Table 1 and Figure 2.

\section{Publication bias}

Funnel plots and Egger's tests were reviewed for two comparisons. For BC formula versus SSRIs for HRSD, the funnel plot was asymmetrical and publication bias was detected (Egger's test $t=-2.37$, 95\% CI -4.8 to -0.35 , $p=0.025)$. However, for BC formula plus SSRIs versus SSRIs for HRSD, the funnel plot was symmetrical and publication bias was not detected (Egger's test $t=-1.41$, $95 \% \mathrm{CI}-15.27$ to $2.91, p=0.17$ ). The number of studies reporting other outcomes was less than 10, and funnel plot evaluation was not appropriate (Fig. 3).

\section{BC Formula Versus SSRIs}

\section{Hamilton Rating Scale for Depression}

Thirty of the 55 studies (3459 participants) used the HRSD to assess severity of depression (Table 1). ${ }^{39-41,45,49,50,53-55,57-61 \text {, }}$ $63,64,68,69,71,76,81-85,87,88,90,92,93$ Several versions of the HRSD, 


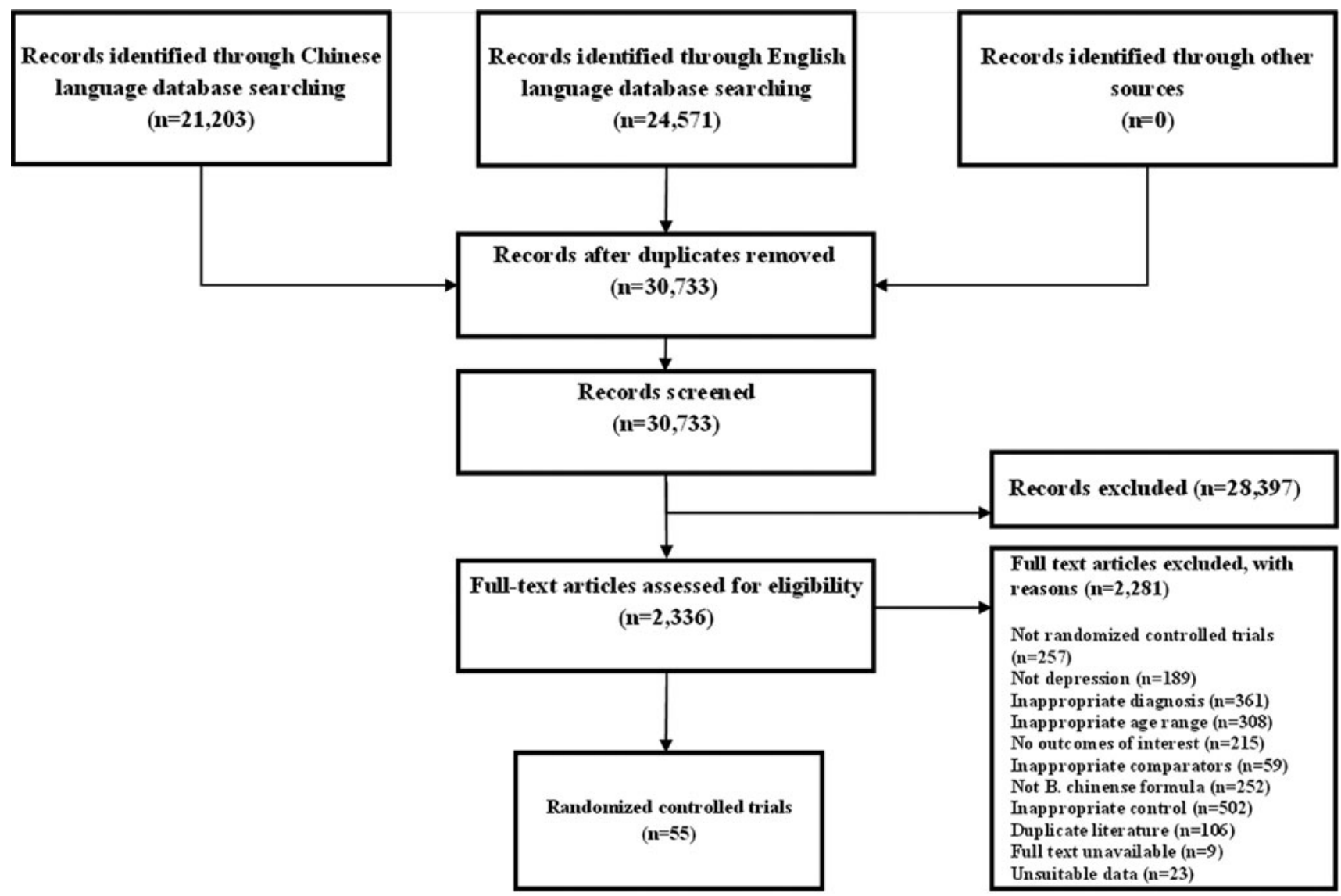

FIG. 1. Flow chart of study selection process.

including HRSD-17 and HRSD-24, were used across these studies. Therefore, SMD was used to pool studies. After 2-12 weeks of treatment, significant reductions in the HRSD scores were seen in BC formula groups compared to SSRI groups (SMD $-0.35[-0.52$ to -0.18$] ; I^{2}=81.2 \%$ ), although heterogeneity was substantial, and quality of the evidence was very low (Fig. 4 and Table 2).

In terms of studies judged at low risk of bias for sequence generation, there were no significant differences between BC formula and SSRIs after subgroup analysis. Treatment for 6 weeks or less in 20 studies favored BC formula (SMD $-0.33[-0.50$ to -0.16$\left.] ; I^{2}=68.5 \%\right)$, as did treatment equal to or greater than 6 weeks in 10 studies (SMD $-0.41[-0.80$ to -0.02$] ; I^{2}=90.2 \%$ ). BC formula reduced depression severity more than the SSRI fluoxetine (SMD -0.42 [ -0.64 to $-0.21] ; I^{2}=85.0 \%, 21$ studies), but there was no statistical difference when compared to the SSRI paroxetine or sertraline. Subgrouping the HRSD version (Version 17) showed that $\mathrm{BC}$ formula was superior to SSRIs (SMD $-0.25[-0.47$ to $-0.04] ; I^{2}=67.8 \%, 11$ studies), although it was not superior in the HRSD-24 subgroup (SMD $-0.19 \quad[-0.46$ to 0.08]; $I^{2}=76.6 \%, 10$ studies). Heterogeneity remained substantial after subgrouping and the reasons were not identifiable.

\section{Zung's Self-Rating Depression Scale}

The SDS was assessed in four studies comparing BC formula to SSRIs (283 participants) ${ }^{53,68,81,88}$ Treatment duration ranged from 3 to 9 weeks. Two studies used fluoxetine as comparator, and the other two used paroxetine. After treatment, BC formula was superior to SSRIs (MD $-1.53[-3.03$ to -0.03$\left.] ; I^{2}=23.8 \%\right)$; low quality evidence (Table 2).

\section{Adverse events}

Twelve (40.0\%) of the studies comparing BC formula with SSRIs reported adverse events. ${ }^{40,45,49,50,55,57,58,63,71,85,87,92}$ People allocated BC formula interventions reported 125 adverse events and people allocated SSRIs reported 286 adverse events. Ten studies reported details about adverse events. In $\mathrm{BC}$ formula groups, 85 detailed adverse events were reported. Dry mouth (16 cases) and loss of appetite (16 cases) were the most common, followed by nausea (9 cases). In the SSRI groups, 196 detailed adverse events were reported, including dry mouth (53 cases), loss of appetite (31 cases), and nausea (14 cases). Two studies reported the nature of the events, but did not specify the number of adverse events in the SSRI group (Table 4). ${ }^{55,63}$

\section{BC Formula Plus SSRIs Versus SSRIs}

\section{Hamilton Rating Scale for Depression}

Twenty-four studies, including 2041 participants, used the HRSD to compare the effects of BC formula plus SSRIs with the same SSRIs alone. $43,44,46-48,51,52,56,62,65-67,70,72-75,77-80,86,89,91$ 


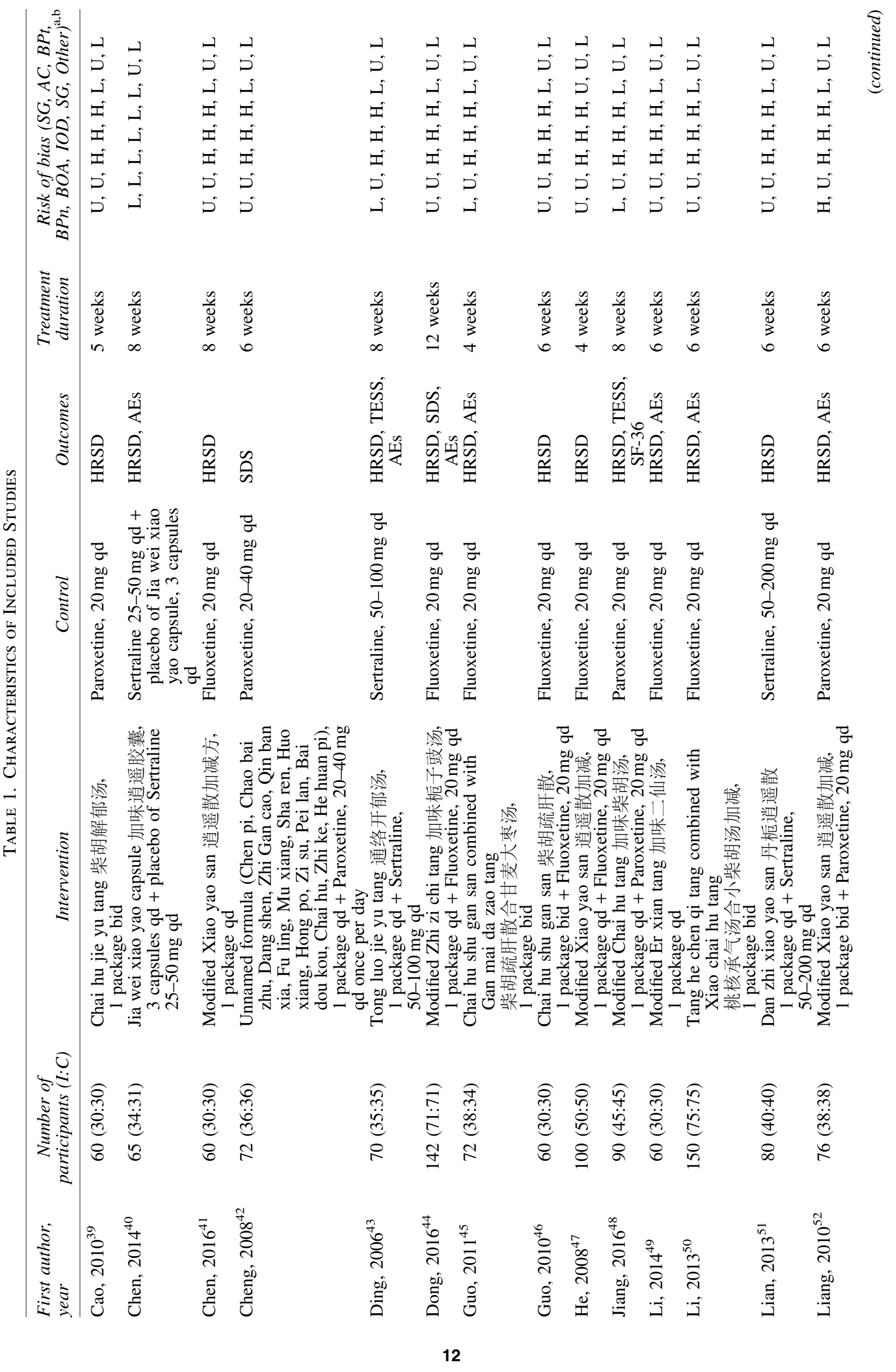




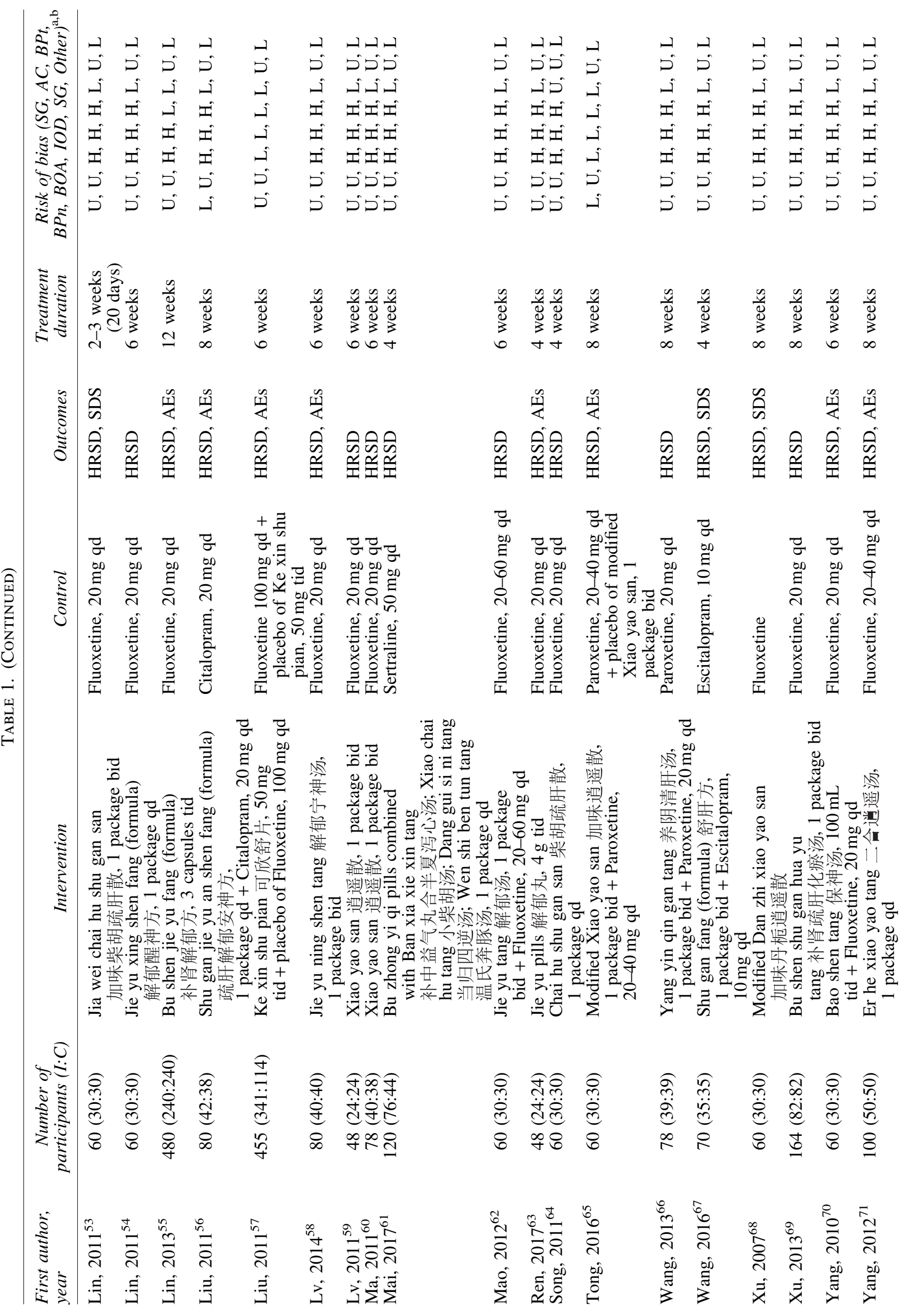




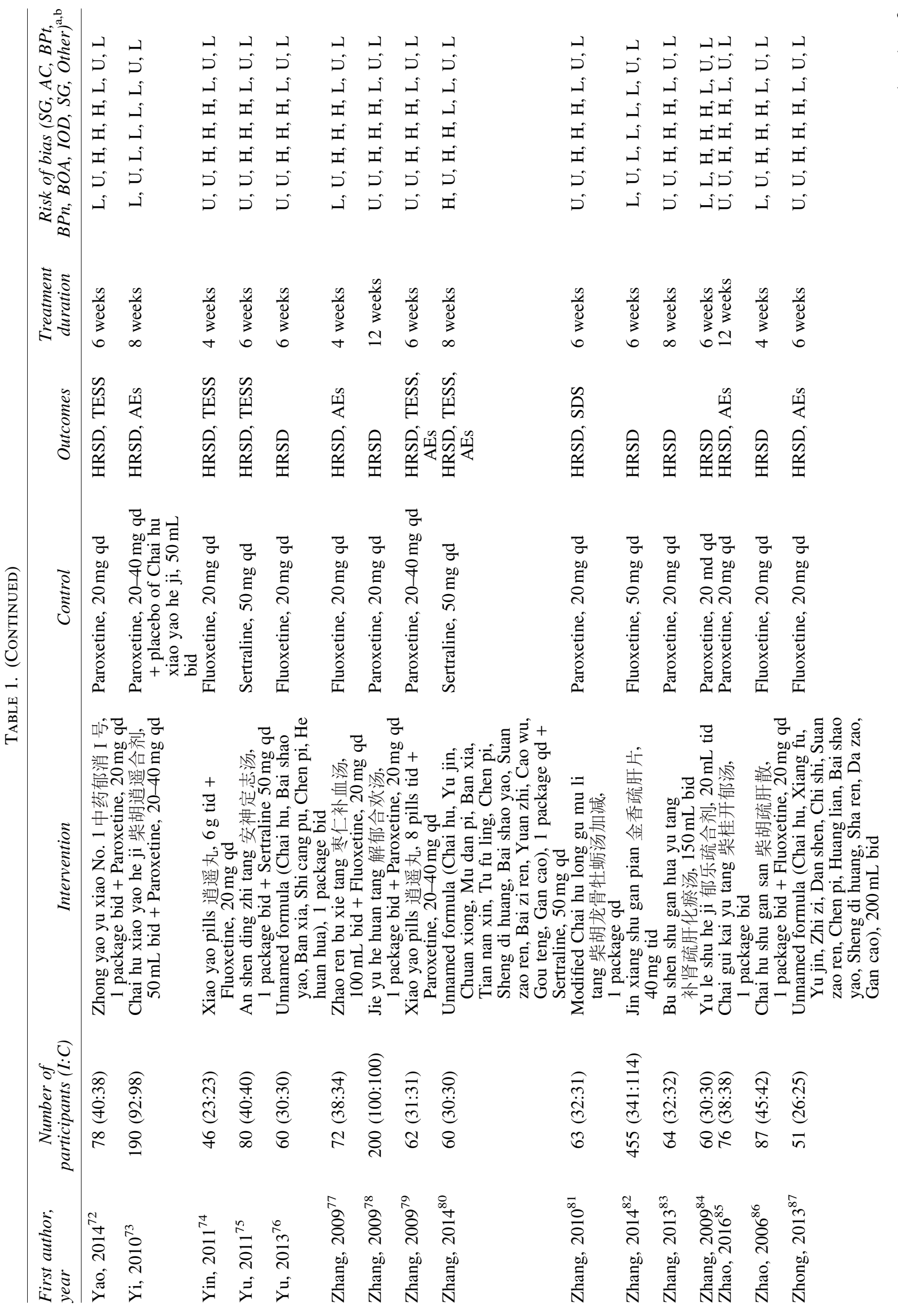




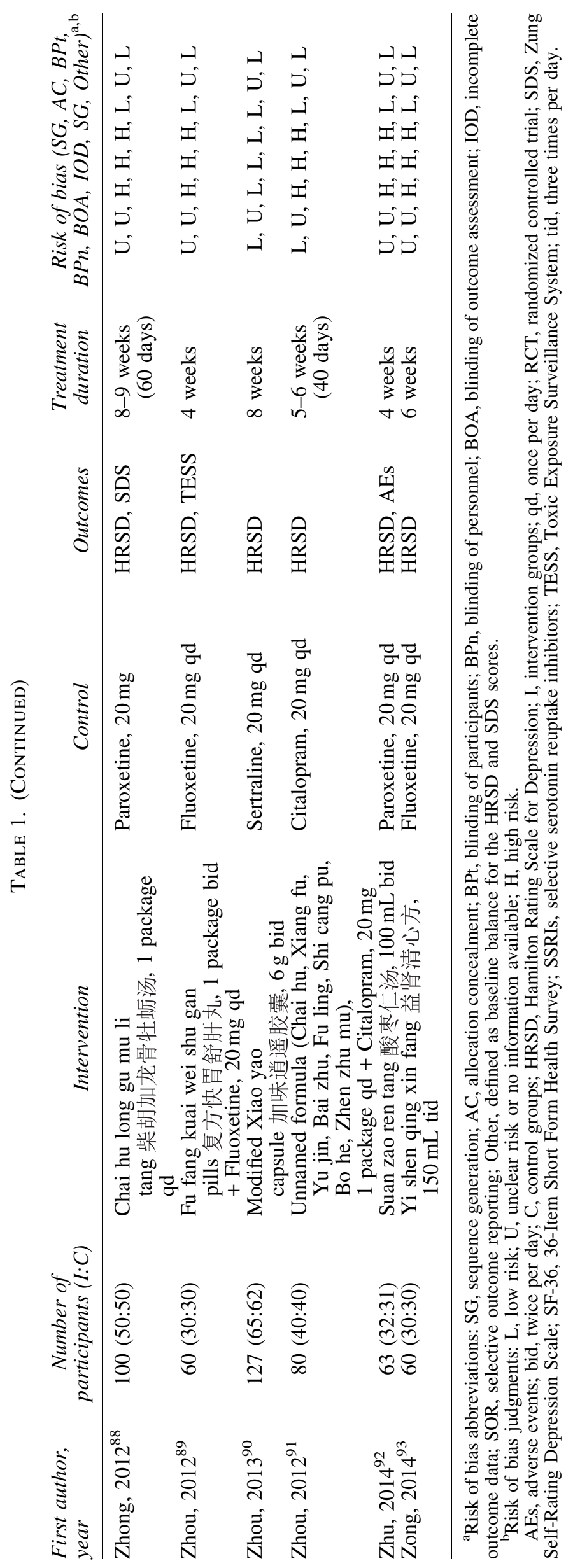




\section{Risk of Bias}

FIG. 2. Risk of bias.

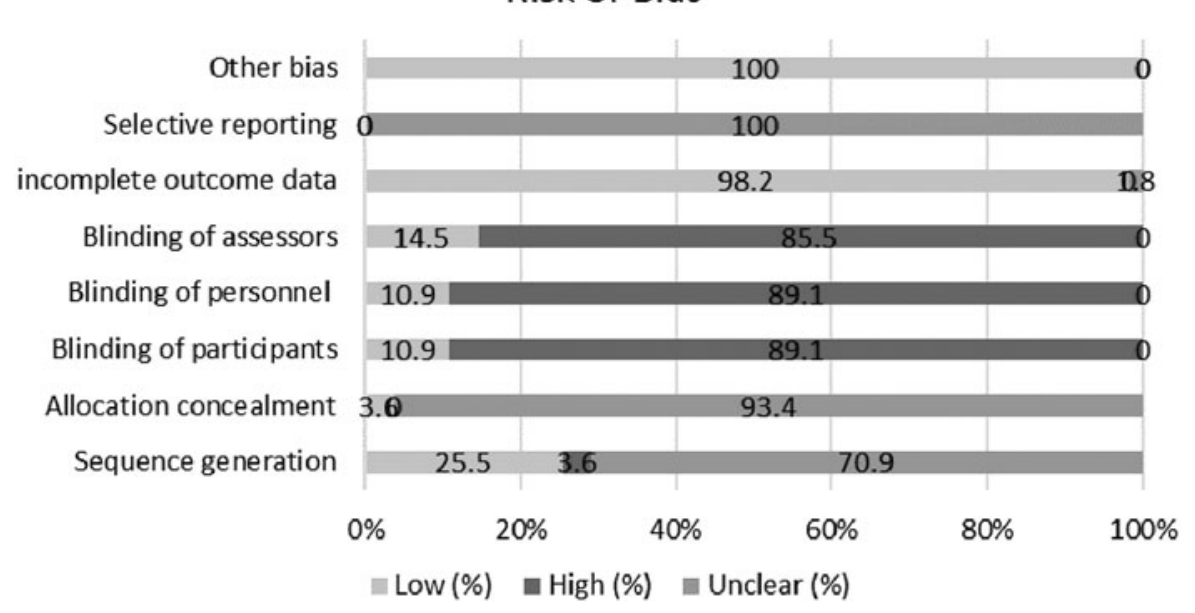

FIG. 3. Funnel plots for publication bias.

(A) BC formula versus SSRIs. (B) BC formula plus SSRIs versus SSRIs. BC, Bupleurum chinense; SSRIs, selective serotonin reuptake inhibitors.
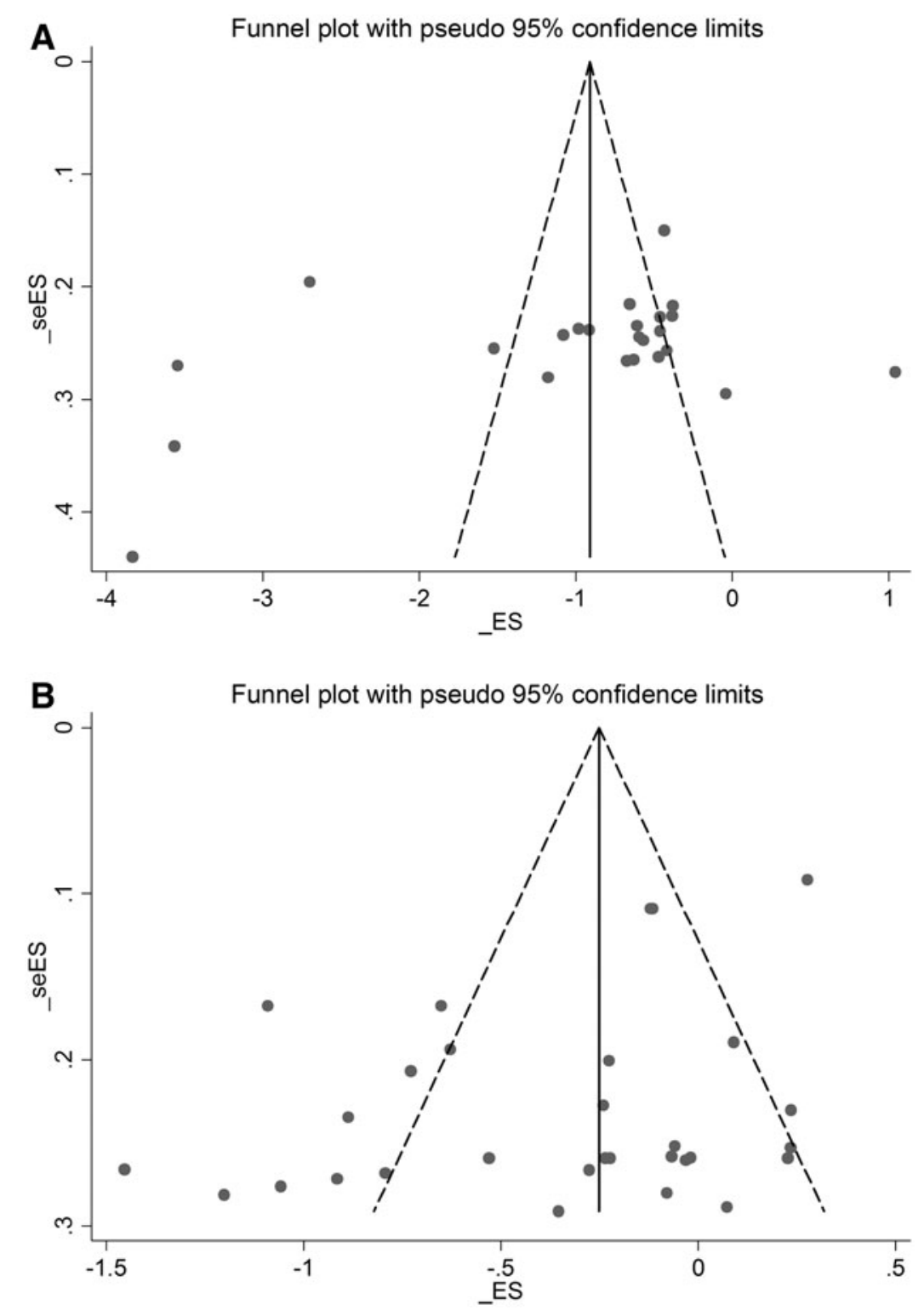


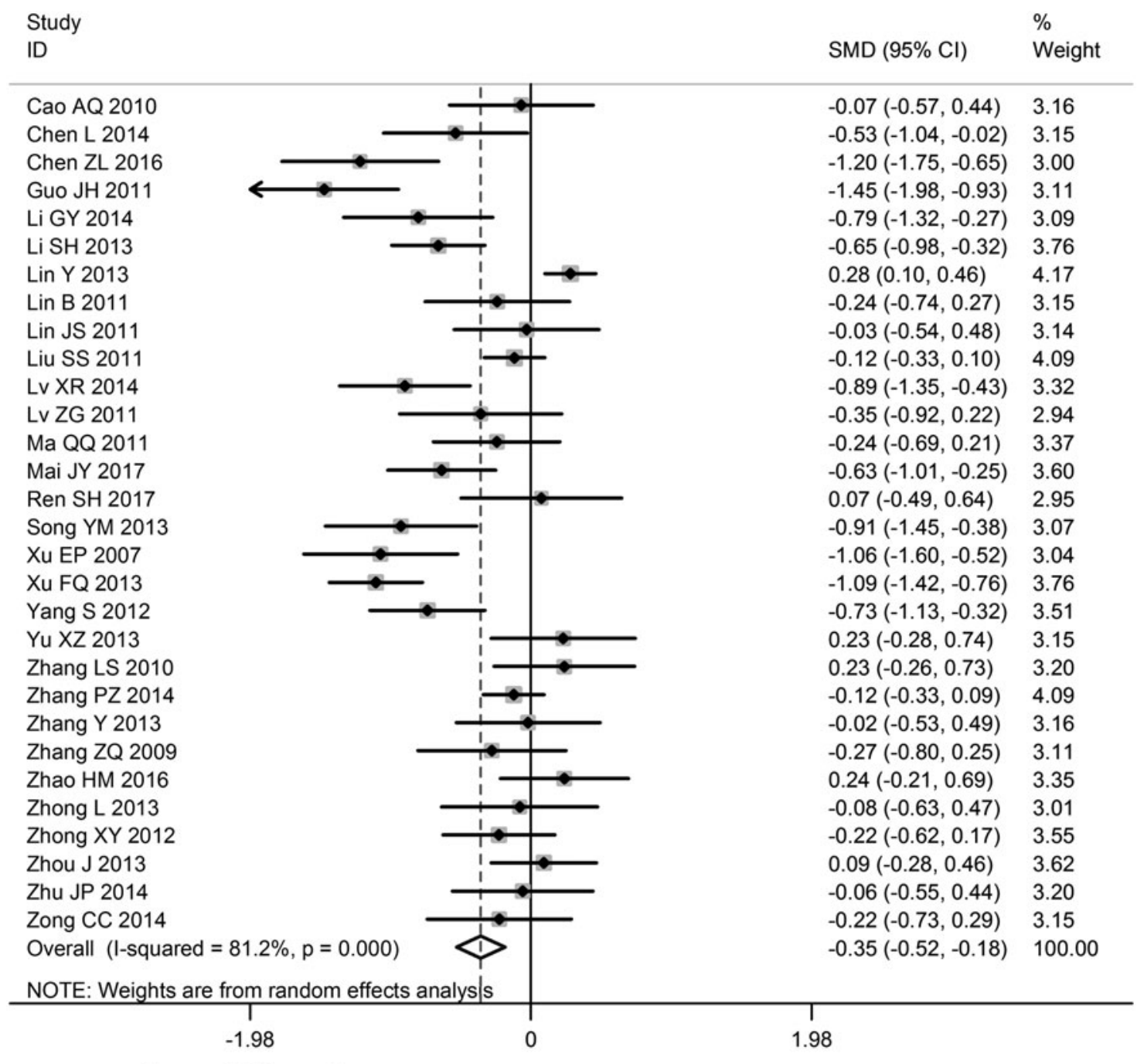

Favors BC formula

Favors SSRIs

FIG. 4. Forest plot comparing BC formula to SSRIs, in terms of Hamilton Rating Scale for Depression. Note that despite a significant difference between groups, studies had risk of bias, which should be considered when interpreting results from this figure.

After 4-12 weeks of treatment, BC formula plus SSRIs reduced the severity of depression more than SSRIs alone (SMD -1.03 [-1.43 to -0.62$] ; I^{2}=94.2 \%$; low quality evidence) (Fig. 5 and Table 3).

In nine studies at low risk of bias for sequence generation, subgrouping also showed that BC formula plus SSRIs was superior to SSRIs alone (SMD -0.90 [-1.38 to -0.43 ]; $I^{2}=90.0 \%$ ). Treatment with BC formula for equal to or less than 6 weeks produced lower HRSD scores between groups (SMD -0.65 [-1.01 to -0.29$] ; I^{2}=87.4 \%, 15$ studies). Treatment for greater than 6 weeks had similar results (SMD -1.63 [-2.42 to -0.84$] ; I^{2}=96.2 \%, 9$ studies). Subgrouping by HRSD version (Version 17) showed that BC formula plus SSRIs was superior to SSRIs alone in 13 studies (SMD -0.67 [ -0.87 to -0.47$\left.], I^{2}=59.4 \%\right)$.

\section{Zung's Self-Rating Depression Scale}

Three studies, including 289 participants, used the SDS to compare BC formula plus SSRIs with SSRIs alone. ${ }^{42,44,67}$
After 4-12 weeks of treatment, SDS scores in the BC formula plus SSRIs groups were significantly lower than those in the SSRI-alone groups (MD -7.19 points $[-8.39$ to -5.99 ]; $I^{2}=0.0 \%$ ); low quality evidence (Table 3 ).

\section{Short Form SF-36 Health Survey}

One RCT evaluated 90 participants using the SF-36 to measure quality of life. ${ }^{48}$ Individual health domains were not reported, but an aggregate score was given. $\mathrm{BC}$ formula plus paroxetine was superior to paroxetine after 8 weeks of treatment (MD 13.53 [9.82-17.24]) (Table 3).

\section{Adverse events}

Ten studies mentioned adverse events. ${ }^{43,44,52,56,65,70,73,77,79,80}$ In the BC formula plus SSRIs groups, 118 events were reported, while in the SSRI groups, 174 events were reported. Nine studies provided adverse event information. Diarrhea was the most common adverse event in the BC formula plus SSRIs 
Table 2. Summary of Findings of Bupleurum Chinense Versus Selective Serotonin Reuptake Inhibitors

\begin{tabular}{|c|c|c|c|c|}
\hline \multirow[b]{3}{*}{ Outcomes } & \multirow{3}{*}{$\begin{array}{c}\text { No. of participants } \\
\text { (Studies) }\end{array}$} & \multirow{3}{*}{$\begin{array}{c}\text { Quality of the } \\
\text { evidence (GRADE) }\end{array}$} & \multicolumn{2}{|c|}{ Anticipated absolute effects } \\
\hline & & & \multicolumn{2}{|c|}{ Assumed risk } \\
\hline & & & SSRIs & Risk difference with $B C$ \\
\hline $\begin{array}{l}\text { Depressive symptoms } \\
\text { (clinician rated) } \\
\text { Hamilton Rating Scale } \\
\text { for Depression } \\
\text { Treatment duration: } \\
\text { mean } 6.4 \text { weeks }\end{array}$ & 3459 (30 RCTs) & $\begin{array}{l}\oplus \bigcirc \bigcirc \bigcirc \\
\text { VERY LOW } \\
\text { VER,3 }\end{array}$ & - & $\begin{array}{l}\text { SMD } 0.35 \text { SD lower } \\
\quad(0.52 \text { lower to } 0.18 \text { lower })\end{array}$ \\
\hline $\begin{array}{l}\text { Depressive symptoms } \\
\text { (patient reported) } \\
\text { Self-rating Depression } \\
\text { Scale } \\
\text { Treatment duration: } \\
\text { mean } 6.5 \text { weeks }\end{array}$ & 283 (4 RCTs) & $\begin{array}{r}\oplus \oplus \bigcirc \bigcirc \\
\mathrm{LOW}^{1,4}\end{array}$ & $\begin{array}{l}\text { The mean Self-rating } \\
\text { Depression Scale } \\
\text { was } 35.12 \text { points }\end{array}$ & $\begin{array}{l}\text { MD } 1.53 \text { points lower } \\
\quad \text { (3.03 lower to } 0.03 \text { lower) }\end{array}$ \\
\hline $\begin{array}{l}\text { Quality of life } \\
\text { Adverse events }\end{array}$ & & & $\begin{array}{l}\text { Not reported } \\
\text { Not reported }\end{array}$ & \\
\hline $\begin{array}{l}\text { The risk in the interventior } \\
\text { intervention (and its } 95 \% \text { CI } \\
\text { GRADE Working Group g } \\
\text { High quality: We are very } \\
\text { Moderate quality: We are n } \\
\text { there is a possibility that it i } \\
\text { Low quality: Our confiden } \\
\text { effect. } \\
\text { Very low quality: We hav } \\
\text { estimate of effect. } \\
{ }^{1} \text { Downgraded one level fo } \\
{ }^{2} \text { Downgrade one level for } \\
{ }^{3} \text { Downgrade one level for } \\
{ }^{4} \text { Downgrade one level for } \\
\end{array}$ & $\begin{array}{l}\text { group (and its } 95 \% \mathrm{CI} \\
\text { rades of evidence. } \\
\text { confident that the true } \\
\text { hoderately confident in } \mathrm{t} \\
\text { substantially different. } \\
\text { ce in the effect estimat } \\
\text { very little confidence } \\
\text { unclear sequence gene } \\
\text { considerable statistical } 1 \\
\text { publication bias. } \\
\text { small sample size. }\end{array}$ & $\begin{array}{l}\text { is based on the assum } \\
\text { effect lies close to that } \\
\text { he effect estimate: The t } \\
\text { e is limited: The true e } \\
\text { in the effect estimate: T } \\
\text { ration and allocation co } \\
\text { heterogeneity. }\end{array}$ & $\begin{array}{l}\text { ed risk in the comparison } \mathrm{g} \\
\text { of the estimate of the effec } \\
\text { rue effect is likely to be clo } \\
\text { ffect may be substantially } \\
\text { The true effect is likely to b } \\
\text { ncealment, lack of blinding }\end{array}$ & $\begin{array}{l}\text { roup and the relative effect of the } \\
\text { se to the estimate of the effect, but } \\
\text { different from the estimate of the } \\
\text { e substantially different from the } \\
\text { of participants and personnel. }\end{array}$ \\
\hline
\end{tabular}

group (17 cases), while constipation was the most common adverse event in the comparator groups (22 cases). Other adverse events included hypersomnia, nausea, and vomiting (Table 4). Eight of the studies reported adverse events on the Toxic Exposure Surveillance System (TESS); after treatment, TESS was lower, indicating less severe and fewer adverse events in the integrative medicine group compared to SSRIs alone (MD $-1.12[-1.69$ to -0.55$] I^{2}=93.2 \%$ ) (Table 3$)$.

\section{Discussion}

BC formula may be effective for improving clinical symptoms and alleviating depression severity. It also appers to be safe, with the number of adverse events in the BC formula groups being half that of the SSRI groups. In addition, meta-analyses for depression severity measured on the HRSD and SDS scales consistently indicated that BC formula has a promising effect when given alongside SSRIs or alone for reducing depression severity. However, heterogeneity and limitations in study methodology should be considered when interpreting these results. Meta-analysis showed that at the end of treatment, there was a significant difference in the HRSD and SDS scores between BC formula and SSRI groups, indicating a potentially clinically important effect. $^{31}$ This result was consistent with previous systematic reviews of herbal medicine for depression. ${ }^{95-98}$

Our review indicates that $\mathrm{BC}$ formula for depression is effective in the short term, similar to acute-phase treatment with antidepressants. ${ }^{99,100}$ When BC formula was used as integrative medicine, the pooled results showed that it may reduce the severity of depression compared to SSRIs alone. The total number of adverse events in the BC formula groups was less than that in SSRI groups.

Improvements of $\mathrm{BC}$ formula groups, either integrative use or used alone, were more obvious after treatment for 6 and 12 weeks. Research indicates that a minimum of 8-10 weeks of treatment is needed for optimal symptom reduction. ${ }^{35,101}$

Contemporary experimental research suggests that herbal compounds or compound combinations act on various targets and pathways to produce antidepressant effects. Preclinical studies have shown these herbs' antidepressant effects are related to their antioxidant and neurotransmitter properties. $^{102,103}$ Xiao yao san/wan has reported antidepressive effects in preclinical studies. ${ }^{104}$ Chai hu shu gan san has also shown its effects are comparable to the antidepressant drug fluoxetine. ${ }^{105,106}$ More research into key herbal compounds of $B$. chinense and $\mathrm{BC}$ formula in animal models or neuronal cells is needed to further elucidate the possible mechanisms of action of this herb.

\section{Limitations of the study}

Included studies were not free from bias. They also had methodological shortfalls, such as unclear sequence generation and allocation concealment, and a lack of blinding of participants and personnel. Considerable heterogeneity was 


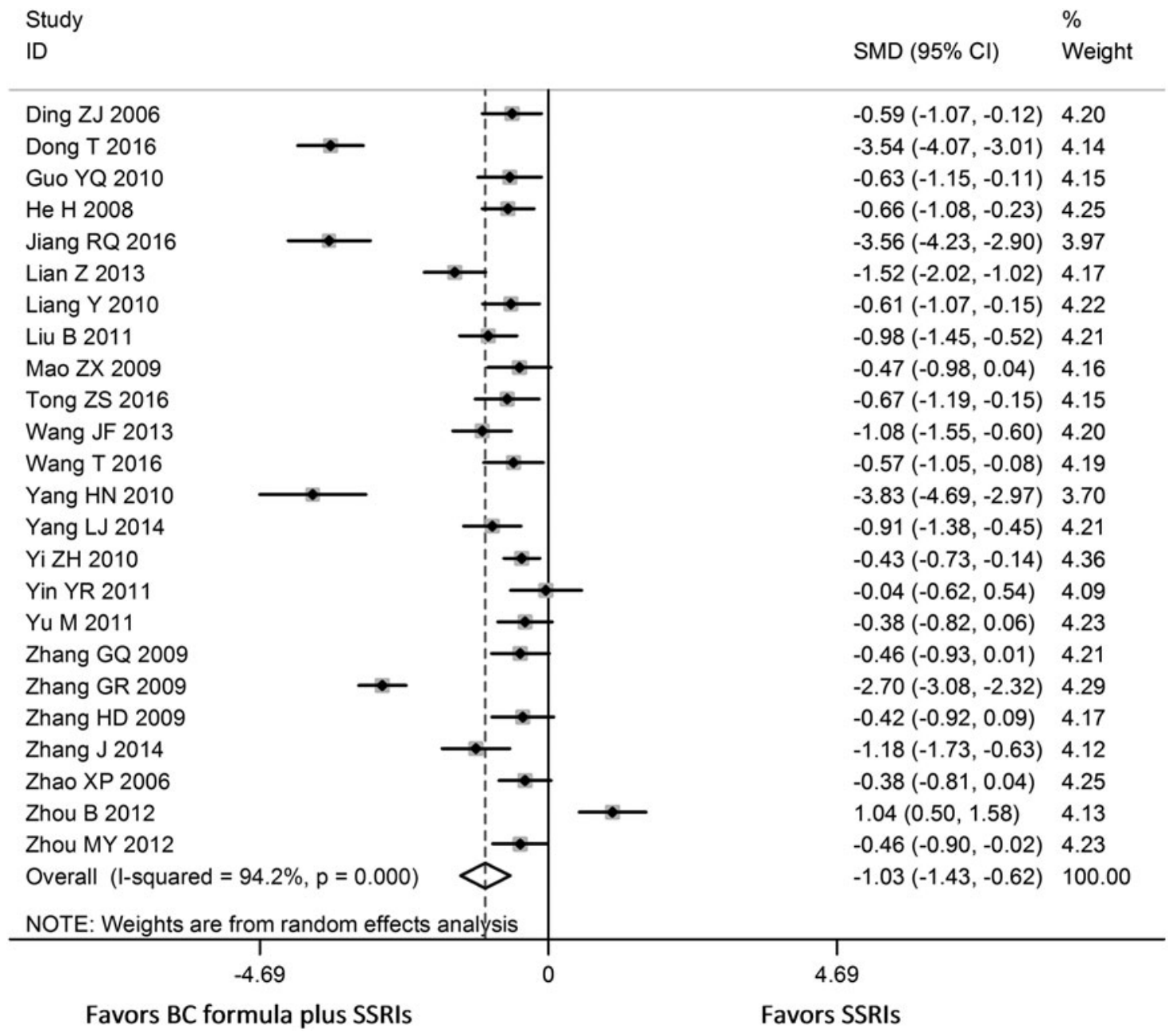

FIG. 5. Forest plot comparing BC formula plus SSRIs to SSRIs alone, in terms of Hamilton Rating Scale for Depression. Note that despite a significant difference between groups, studies had risk of bias, which should be considered when interpreting results from this figure.

also noted and could not be resolved by subgroup analysis. It may be due to variable etiologies, severity of depression, disease history, study protocols, and outcome measurements. The BC formula interventions were considered to be the same and therefore merged in meta-analysis. However, there were differences between studies in terms of treatment duration, other herbal ingredients, dosage, and medication compliance that may have contributed to heterogeneity.

\section{Future studies}

Future clinical studies of BC formula for MDD need rigorous methodology, including clearly stated methods of sequence generation and allocation concealment. Future studies should also publish their protocols and be registered with a clinical trial registry to minimize reporting bias and increase transparency in reporting of the results.

Cause of depression, severity, disease history, treatment preference, and expectancy should be taken into consideration when designing trials and selecting participants. Selecting similar participants, in terms of etiology, age range, and severity, may help to achieve more comparable and reliable results. Assessing clinically important outcomes, such as relapse and remission of depression, quality of life, functional capacity, and suicidality, would provide a comprehensive understanding of the effect of BC formula. As for treatment expectancy, it may influence treatment effect and modify clinical decisions, and should be considered when designing trials and drawing conclusions.

Treatment duration in the included clinical trials ranged from 2 to 12 weeks and only a few reported follow-up data. Depression is a lifelong disease and should be monitored every 1-2 weeks during treatment. Follow-up assessment would provide long-term data and further strengthen the evidence.

Future clinical studies should also report the items required by the Consolidated Standards of Reporting Trials $(\text { CONSORT })^{107}$ and its extensions for herbal medicine. ${ }^{108,109}$ Informative reporting of trial participants, reason for intervention selection, comparator, and results of validated outcome measures will provide high-level clinical evidence, and will benefit practitioners, researchers, patients, and knowledge translation. 
Table 3. Summary of Findings of Bupleurum chinense Plus Selective Serotonin Reuptake Inhibitors Versus SElEctive Serotonin Reuptake Inhibitors

\begin{tabular}{|c|c|c|c|c|}
\hline \multirow[b]{3}{*}{ Outcomes } & \multirow{3}{*}{$\begin{array}{l}\text { No. of } \\
\text { participants } \\
\text { (Studies) }\end{array}$} & \multirow{3}{*}{$\begin{array}{l}\text { Quality of the } \\
\text { evidence } \\
\text { (GRADE) }\end{array}$} & \multicolumn{2}{|c|}{ Anticipated absolute effects } \\
\hline & & & \multicolumn{2}{|c|}{ Assumed risk } \\
\hline & & & SSRIs & Risk difference with $B C$ \\
\hline $\begin{array}{l}\text { Depressive symptoms } \\
\text { (clinician rated) } \\
\text { Hamilton Rating Scale } \\
\text { for Depression } \\
\text { Treatment duration: } \\
\text { mean } 6.6 \text { weeks }\end{array}$ & 2041 (24 RCTs) & $\begin{array}{l}\oplus \oplus \oplus \bigcirc \bigcirc \\
\text { LOW }^{1,2}\end{array}$ & - & $\begin{array}{l}\text { SMD 1.03 SD lower } \\
\quad(1.43 \text { lower to } 0.62 \text { lower })\end{array}$ \\
\hline $\begin{array}{l}\text { Depressive symptoms } \\
\text { (patient reported) } \\
\text { Self-rating Depression } \\
\text { Scale } \\
\text { Treatment duration: } \\
\text { mean } 7.3 \text { weeks }\end{array}$ & 289 (3 RCTs) & $\begin{array}{l}\oplus \oplus \bigcirc \bigcirc \\
\mathrm{LOW}^{1,3}\end{array}$ & $\begin{array}{l}\text { The mean Self-rating } \\
\text { Depression Scale was } \\
44.90 \text { points }\end{array}$ & $\begin{array}{l}\text { MD } 7.19 \text { points lower } \\
\text { (8.39 lower to } 5.99 \text { lower) }\end{array}$ \\
\hline $\begin{array}{l}\text { Quality of life } \\
\text { Short Form SF-36 } \\
\text { Health Survey } \\
\text { Treatment duration: } \\
8 \text { weeks }\end{array}$ & $90(1 \mathrm{RCT})$ & $\begin{array}{l}\oplus \oplus \oplus \bigcirc \bigcirc \\
\mathrm{LOW}^{1,3}\end{array}$ & $\begin{array}{c}\text { The SF- } 36 \text { was } \\
60.68 \text { points }\end{array}$ & $\begin{array}{l}\text { MD } 13.53 \text { points higher } \\
\text { ( } 9.82 \text { higher to } 17.24 \text { higher) }\end{array}$ \\
\hline $\begin{array}{l}\text { Adverse events } \\
\text { TESS } \\
\text { Treatment duration: } \\
\quad 6.25 \text { weeks }\end{array}$ & 546 (8 RCTs) & $\begin{array}{l}\oplus \oplus \oplus \bigcirc \bigcirc \\
\mathrm{LOW}^{1,2}\end{array}$ & $\begin{array}{l}\text { The mean TESS } \\
\text { was } 4.51 \text { points }\end{array}$ & $\begin{array}{l}\text { MD } 1.12 \text { lower } \\
\text { (1.69 lower to } 0.55 \text { lower })\end{array}$ \\
\hline
\end{tabular}

The risk in the intervention group (and its 95\% CI) is based on the assumed risk in the comparison group and the relative effect of the intervention (and its $95 \% \mathrm{CI}$ ).

GRADE Working Group grades of evidence.

High quality: We are very confident that the true effect lies close to that of the estimate of the effect.

Moderate quality: We are moderately confident in the effect estimate: The true effect is likely to be close to the estimate of the effect, but there is a possibility that it is substantially different.

Low quality: Our confidence in the effect estimate is limited: The true effect may be substantially different from the estimate of the effect.

Very low quality: We have very little confidence in the effect estimate: The true effect is likely to be substantially different from the estimate of effect.

${ }^{1}$ Downgraded one level for unclear sequence generation and allocation concealment, lack of blinding of participants and personnel.

${ }^{2}$ Downgrade one level for considerable statistical heterogeneity.

${ }^{3}$ Downgrade one level for small sample size.

Table 4. Adverse Events

\begin{tabular}{|c|c|c|c|}
\hline Comparisons & No. of studies & Intervention group adverse events & Control group adverse events \\
\hline BC formula vs. SSRIs & 12 & $\begin{array}{l}\text { Total adverse events }=125 \\
\text { Most common events (number of cases) } \\
\text { - Dry month (16) } \\
\text { - Loss of appetite (16) } \\
\text { - Nausea (9) } \\
\text { - Headache (8) } \\
\text { - Restlessness (5) } \\
\text { - Hypersomnia (5) } \\
\text { - Dizziness (4) } \\
\text { - Hypersomnia (5) } \\
\text { - Sweating (3) } \\
\text { - Nasal congestion (3) }\end{array}$ & $\begin{array}{l}\text { Total adverse events }=286 \\
\text { Most common events (number of cases) } \\
\text { - Dry mouth (53) } \\
\text { - Loss of appetite (31) } \\
\text { - Nausea (14) } \\
\text { - Constipation (12) } \\
\text { - Dizziness (11) } \\
\text { - Sweating (8) } \\
\text { - Insomnia (7) } \\
\text { - Nausea and loss of appetite (7) } \\
\text { - Insomnia (5) } \\
\text { - Hypersomnia (5) }\end{array}$ \\
\hline $\begin{array}{l}\text { BC formula plus } \\
\text { SSRIs vs. SSRIs }\end{array}$ & 10 & $\begin{array}{l}\text { Total adverse events }=118 \\
\text { Most common events (number of cases) } \\
\text { - Diarrhea (17) } \\
\text { - Nausea (14) } \\
\text { - Constipation (12) } \\
\text { - Hypersomnia (9) } \\
\text { - Blurred vision (9) } \\
\text { - Dry mouth (8) } \\
\text { - Headache (7) } \\
\text { - Nausea and vomiting (7) } \\
\text { - Dizziness (7) } \\
\text { - Sweating (7) }\end{array}$ & $\begin{array}{l}\text { Total adverse events = } 174 \\
\text { Most common events (number of cases) } \\
\text { - Constipation (22) } \\
\text { - Nausea and vomiting (18) } \\
\text { - Nausea (15) } \\
\text { - Hypersomnia (15) } \\
\text { - Dry mouth (13) } \\
\text { - Insomnia (11) } \\
\text { - Diarrhea (11) } \\
\text { - Blurred vision (11) } \\
\text { - Sweating (11) } \\
\text { - Headache (5) }\end{array}$ \\
\hline
\end{tabular}




\section{Conclusions}

$\mathrm{BC}$ formula alone or given as integrative medicine with SSRIs may reduce depression severity. The current evidence should be interpreted with caution due to bias and methodological shortfalls in the included studies, and heterogeneity in meta-analysis. BC formula does not appear to increase the risk of adverse events. New studies with rigorous methodologies in well-defined populations, including short- and long-term follow-up, will help validate the promising evidence identified in this review.

\section{Acknowledgments}

The authors sincerely acknowledge the support of staff at the Discipline of Chinese Medicine, School of Health and Biomedical Sciences of RMIT University, and research staff at the Evidence-Based Medicine and Clinical Research Service Group of the Guangdong Provincial Hospital of Traditional Chinese Medicine, in providing resources. We also acknowledge the help of staff at the Department of Psychology and Sleep Medicine of the Guangdong Provincial Hospital of Traditional Chinese Medicine. This work was supported by the China-Australia International Research Centre for Chinese Medicine (CAIRCCM) - a joint initiative of RMIT University, Australia, and the Guangdong Provincial Academy of Chinese Medical Sciences, China. We also received additional funding from the Ministry of Science \& Technology of China (International Cooperation Project, Grant No. 2012DFA31760) and Guangdong Provincial Hospital of Traditional Chinese Medicine (Grant No. YN2016QL05 and YN2015QN23).

\section{Author Disclosure Statement}

No competing financial interests exist.

\section{Supplementary Material}

Supplementary Table S1

\section{References}

1. American Psychiatric Association. Practice Guideline for the Treatment of Patients with Major Depressive Disorder. Washington, DC: American Psychiatric Association, 2010.

2. Shahrokh NC, Hales RE, Phillips KA, Yudofsky SC. The Language of Mental Health: A Glossary of Psychiatric Terms. Washington, DC: American Psychiatric Publishing, 2011.

3. Whiteford HA, Degenhardt L, Rehm J, et al. Global burden of disease attributable to mental and substance use disorders: Findings from the Global Burden of Disease Study 2010. Lancet 2013;382:1575-1586.

4. American Psychiatric Association. Diagnostic and Statistical Manual of Mental Disorders (DSM-V). Arlington, VA: American Psychiatric Association, 2013.

5. Andrade L, Caraveo-Anduaga JJ, Berglund P, et al. The epidemiology of major depressive episodes: Results from the International Consortium of Psychiatric Epidemiology (ICPE) Surveys. Int J Methods Psychiatr Res 2003; $12: 3-21$
6. Murray CJ, Lopez AD. Alternative projections of mortality and disability by cause 1990-2020: Global Burden of Disease Study. Lancet 1997;349:1498-1504.

7. Murray CJ, Vos T, Lozano R, et al. Disability-adjusted life years (DALYs) for 291 diseases and injuries in 21 regions, 1990-2010: A systematic analysis for the Global Burden of Disease Study 2010. Lancet 2012;380:21972223.

8. Kessler RC, Ormel J, Petukhova M, et al. Development of lifetime comorbidity in the World Health Organization world mental health surveys. Arch Gen Psychiatry 2011; 68:90-100.

9. Simon GE. Evidence review: Efficacy and effectiveness of antidepressant treatment in primary care. Gen Hosp Psychiatry 2002;24:213-224.

10. Arroll B, Elley CR, Fishman T, et al. Antidepressants versus placebo for depression in primary care. Cochrane Database Syst Rev 2009:CD007954. DOI: 10.1002/ 14651858.CD007954.

11. Anderson IM, Nutt DJ, Deakin JF. Evidence-based guidelines for treating depressive disorders with antidepressants: A revision of the 1993 British Association for Psychopharmacology guidelines. J Psychopharmacol 2000;14:3-20.

12. National Collaborating Centre for Mental Health. National Institute for Health and Clinical Excellence: Guidance. Depression in Adults with a Chronic Physical Health Problem: Treatment and Management. Leicester, UK: British Psychological Society. The British Psychological Society \& The Royal College of Psychiatrists, 2010.

13. Serna MC, Real J, Cruz I, et al. Monitoring patients on chronic treatment with antidepressants between 2003 and 2011: Analysis of factors associated with compliance. BMC Public Health 2015;15:1184.

14. Jakobsen JC, Katakam KK, Schou A, et al. Selective serotonin reuptake inhibitors versus placebo in patients with major depressive disorder. A systematic review with meta-analysis and Trial Sequential Analysis. BMC Psychiatry 2017;17:58.

15. Uher R, Farmer A, Henigsberg N, et al. Adverse reactions to antidepressants. Br J Psychiatry 2018;195:202-210.

16. Cleare A, Pariante CM, Young AH, et al. Evidence-based guidelines for treating depressive disorders with antidepressants: A revision of the 2008 British Association for Psychopharmacology guidelines. J Psychopharmacol 2015;29:459-525.

17. Demyttenaere K. Risk factors and predictors of compliance in depression. Eur Neuropsychopharmacol 2003; 13(Suppl 3):S69-S75.

18. Cantrell CR, Eaddy MT, Shah MB, et al. Methods for evaluating patient adherence to antidepressant therapy: A real-world comparison of adherence and economic outcomes. Med Care 2006;44:300-303.

19. Geddes JR, Carney SM, Davies C, et al. Relapse prevention with antidepressant drug treatment in depressive disorders: A systematic review. Lancet 2003;361:653661.

20. Badger F, Nolan P. Use of self-chosen therapies by depressed people in primary care. J Clin Nurs 2007;16: 1343-1352.

21. Wu P, Fuller C, Liu X, et al. Use of complementary and alternative medicine among women with depression: Results of a national survey. Psychiatr Serv 2007;58:349356. 
22. de Jonge $\mathrm{P}$, Wardenaar KJ, Hoenders HR, et al. Complementary and alternative medicine contacts by persons with mental disorders in 25 countries: Results from the World Mental Health Surveys. Epidemiol Psychiatr Sci 2018;27:552-567.

23. Kessler RC, Soukup J, Davis RB, et al. The use of complementary and alternative therapies to treat anxiety and depression in the United States. Am J Psychiatry 2001; 158:289-294.

24. Asher GN, Gartlehner G, Gaynes BN, et al. Comparative benefits and harms of complementary and alternative medicine therapies for initial treatment of major depressive disorder: Systematic review and meta-analysis. J Altern Complement Med 2017;23:907-919.

25. Gartlehner G, Gaynes BN, Amick HR, et al. AHRQ Comparative Effectiveness Reviews. Nonpharmacological Versus Pharmacological Treatments for Adult Patients with Major Depressive Disorder. Rockville, MD: Agency for Healthcare Research and Quality (US), 2015.

26. El-Alfy AT, Abourashed EA, Matsumoto RR. Nature against depression. Curr Med Chem 2012;19:2229-2241.

27. Iovieno N, Dalton ED, Fava M, Mischoulon D. Secondtier natural antidepressants: Review and critique. J Affect Dis 2011;130:343-357.

28. Yang F, Dong X, Yin X, et al. Radix Bupleuri: A review of traditional uses, botany, phytochemistry, pharmacology, and toxicology. Biomed Res Int 2017;2017:7597596.

29. Zhang Y, Han M, Liu Z, et al. Chinese herbal formula xiao yao san for treatment of depression: A systematic review of randomized controlled trials. Evid Based Complement Alternat Med 2012;2012:931636.

30. Sun Y, Xu X, Zhang J, Chen Y. Treatment of depression with Chai $\mathrm{Hu}$ Shu Gan San: A systematic review and meta-analysis of 42 randomized controlled trials. BMC Complement Altern Med 2018;18:66.

31. Higgins J, Green S, eds. Cochrane Handbook for Systematic Reviews of Interventions Version 5.1.0 [updated March 2011]. The Cochrane Collaboration, 2011.

32. Chinese Society of Psychiatry. Chinese Classification of Mental Disorders (CCMD-3). Jinan, People's Republic of China: Shandong Science Technology Press, 2011.

33. World Health Organization. The ICD-10 classification of mental and behavioural disorder: Clinical descriptions and diagonostic guidelines. Geneva: World Health Organization 1992.

34. Bauer M, Pfennig A, Severus E, et al. World Federation of Societies of Biological Psychiatry (WFSBP) guidelines for biological treatment of unipolar depressive disorders, part 1: Update 2013 on the acute and continuation treatment of unipolar depressive disorders. World J Biol Psychiatry 2013;14:334-385.

35. Qaseem A, Barry MJ, Kansagara D. Nonpharmacologic versus pharmacologic treatment of adult patients with major depressive disorder: A clinical practice guideline from the American College of Physicians. Ann Intern Med 2016; 164:350-359.

36. Hamilton M. A rating scale for depression. J Neurol Neurosurg Psychiatry 1960;23:56-62.

37. Zung WW. A Self-rating Depression Scale. Arch Gen Psychiatry 1965;12:63-70.

38. Montgomery SA, Smeyatsky N, de Ruiter M, Montgomery DB. Profiles of antidepressant activity with the Montgomery-Asberg Depression Rating Scale. Acta Psychiatr Scand Suppl 1985;320:38-42.
39. Cao AQ, Guo YL, Zhang XQ. Treatment of liver stagnation and blood deficiency type depression with Chai $\mathrm{Hu}$ Jie Yu Tang-30 cases. Chin Med Mod Distance Educ China 2010;8:23.

40. Chen L. The effect of Jia Wei Xiao Yao Capsules on the treatment of mild to moderate depression of the stagnation turned to fire syndrome, 62 cases. Beijing: Beijing University of Chinese Medicine, 2014.

41. Chen ZL, Wu ZG. The effect of Modified Xiao Yao san for depression of Liver Qi stagnation with Spleen deficiency syndrome. J Integr Res Chin Med Western Med 2016;6:298-300.

42. Cheng K, Yan H, Duan KJ. An observation of the effects of a self-compiled Chinese medicine formula for depression. Clin J Chin Med 2008;4:375-376.

43. Ding ZJ. A controlled study of Tong Luo Kai Yu Tang combined with Setraline for the treatment of depression. Health Vocational Educ 2006;22:147-148.

44. Dong T. A Clinical study of Jia Wei Zhi Zi Tang for the treatment of depression. Henan Tradit Chin Med 2016;36: 867-868.

45. Guo JH, Wang SS, Fan R. Clinical observation on the effect of Chai Hu Shu Gan San combined with Modified Gan Mai Da Zao Tang for the treatment of postpartum depression. J North Pharm 2011;8:18-20.

46. Guo YQ, Su YM. 30 cases of treating Liver Qi stagnation type depression using an integration of Chinese medicine and western medicine. Tradit Chin Med Res 2010;23:46-47.

47. He H, Ren Lr. Clinical observation of Modified Xiao Yao San combined with fluoxetine for the treatment of postpartum depression. Hubei J Tradit Chin Med 2008;30: 37-38.

48. Jiang RQ, Wu MJ, He GJ. The effect of modified Chai hu tang on serum inflammatory factors and quality of life in patients with depression. Chin Arch Tradit Chin Med 2016;5:1250-1252.

49. Li GY. Clinical Study of Modified Er Xian Tang for Depression During Menopause. Jinan: Shangdong University of Chinese Medicine, 2014.

50. Li SH, Li JQ, Li WQ, et al. The effect of Chinese medicine and management measures for postpartum depression. Chin J Ethnomed Ethnopharm 2013;22:161-163.

51. Lian Z, Wu Q, Zhao SN. A controlled study of setraline combined with Dan Zhi Xiao Yao San for depression. J Clin Psychosom Dis 2013;19:237-238.

52. Liang Y. 38 cases of Xiao Yao San combined with Paroxetine for the treatment of depression. Shanxi Chin Med 2010;31:677-678.

53. Lin B, Xia J. Clinical study of modified Chai Hu Shu Gan San for the treatment of depression. J N Chin Med 2011; 43:36-37.

54. Lin JS, Guo XL, Chen JX, Guo ML. Clinical observation of Jie Yu Xing Pi Fang for the treatment of deprssion with Liver Qi Stagnation syndrome. China J Tradit Chin Med Pharm 2011;26:338-340.

55. Lin Y, Yang LQ, Yang XM, et al. The effect of tonify the Kidneys and remove stagnation methods for depression patients with Liver Qi stagnation and Kidney defiencey syndrome. China J Tradit Chin Med Pharm 2013;31: 2143-2415.

56. Liu B. Clinical Study of Shu Gan Jie Yu An Shen Formula for the Treatment of Moderate Depression. Henan: Henan University of Chinese Medicine, 2011. 
57. Liu SS, Chen WY, Liu FY, et al. Stage III clincal study of Ke Xin Shu for the treatment of mild to moderate depression in patients with Liver Qi stagnation and Spleen deficiency syndrome. Chin J New Drugs Clin Remedies 2011;30:107-110.

58. Lv XR, Li FH. 40 cases of Jie Yu Ning Shen Tang for the treatment of depression. Nei Mongol J Tradit Chin Med 2014;33:11-12.

59. Lv ZG. Clinical Study of Regulate Liver, Remove Stagnation and Tonify Spleen Method for Treating Depression of Liver Qi Stagnation and Spleen Defiency Syndrome. Changchun: Changchun University of Chinese Medicine, 2011.

60. Ma QQ, Lin H. Xiao Yao San plus modified Suan Zao Ren Tang for the treatment of mild depression-40 cases. Henan Tradit Chin Med 2011;31:1063-1064.

61. Mai JY, Wai LSQ, Gong D, et al. Clinical observation of treating depression using the Spleen-Stomach theory and syndrome differentiation using the six-meridian theory. $\mathrm{J}$ Liaoning Univ Tradit Chin Med 2017;10:150-153.

62. Mao ZX, Li GQ, Yang Y, et al. 30 clinical cases of Jie Yu Tang plus fluoxetine for the treatment of depression with the Liver Qi stagnation and Spleen Deficiency syndrome. Hebei Chin Med 2012;34:223-226.

63. Ren SH, Yang CX. The clincal effects of Jie Yu Wan for the treatment of mild to moderate postpartum depression. J Guang Ming Chin Med 2017;2:225-226.

64. Song YM. 30 cases of Shu Gan Jie Yu Li Qi method for the treatment of depression. Chin Med Mod Distance Educ China 2011;9:7.

65. Tong ZS, Liu B, Xu Y. Randomised controlled trial of Paroxetine combined with modified Xiao Yao san for the treatment of depression. Sichuan Ment Health 2016;29: 31-34.

66. Wang JF. The effect of Yang Yin Qing Gan Tang combined with paroxetine on the physical symptoms of depression. Med J Chin Peoples Health 2013;25:64.

67. Wang T, Wang X, Fan HF, et al. Clinical observation of modified Shu Gan Fang combined with Escitalopram for the treatment of depression. Hebei Chin Med 2016;8: 1184-1186.

68. Xu EP. Modified Dan Zhi Xiao Yao Capsules for the Treatment of Depression, a Clinical and Mechanistic Study. Nanjing University of Chinese Medicine, 2007.

69. Xu FQ, Zhang Y, Zhang LY. Clinical study of Bu Shen Shu Gan Hua Yu Tang for depression during perimenopause-82 cases. Hebei Chin Med 2013;35:333-334.

70. Yang HN, Wang Q, Jiang L, Qiao J. Clinical study of Bao Shen Tang combined with fluoxetine for the treatment of depression. J Chin Med Pharmacol 2010;38:108-110.

71. Yang S, Liu DY. Clinical observation of Er He Xiao Yao Tang plus Fluoxetine for the treatment of depression. J Sichuan Tradit Chin Med 2012;30:77-78.

72. Yao LJ, Gu ZZ, Ji B, et al. Clinical observation of Yu Xiao Formula 1 for the treatment of Liver Qi stagnation syndrome depression. Chin J Tradit Med Sci Technol 2014;21:546-547.

73. Yi ZH, Zhu LP, Long B, et al. Clinical observation of paroxetine plus Chai $\mathrm{Hu}$ Xiao Yao San for the treatment of depression. Chin J Integr Tradit Western Med 2010;30: 1257-1260.

74. Yin YR, Wu LN, Zhang M. A study of fluoxetine plus Chinese Herbal Medicine for the treatment of postpartum depression due to labor induction. J Clin Exp Med 2011; 10:1513-1515.

75. Yu M, Yu X, Li N, et al. Controlled study of An Shen Ding Zhi Tang plus Setraline for depression. Hebei Med J 2011;33:2054-2055.

76. Yu XP, Zhang X, Liu XY. Clinical observation of regulating Qi and resolve phlegm treatment method for depression. Liaoning J Tradit Chin Med 2013;40:22922293.

77. Zhang GQ, Zhang GP, Ai CM, et al. Clinical observations of 38 cases of Zao Ren Bu Xue Tang plus Fluoxetine for the treatment of depression during menopause. Beijing $\mathrm{J}$ Tradit Chin Med 2009;28:873-874.

78. Zhang GR, Sun Q, Wang JC, et al. Clinical observation of Jie Yu He Huan Tang for the treatment of depression. Qinghai Med J 2009;39:84-85.

79. Zhang HD, Su H. Controlled study of paroxetine plus Xiao Yao Wan for the treatment of depression. Mod J Integr Tradit Chin Western Med 2009;18:4060-4063.

80. Zhang J, Tang QP, Xu WJ. Observation on the effect of Chinese Herbal medicine combined with Setraline for the treatment of depression. Chin Arch Tradit Chin Med 2014;32:2800-2802.

81. Zhang LS. Clinical observation of Modified Chai Hu Long $\mathrm{Gu} \mathrm{Mu} \mathrm{Li}$ Formula for the treatment of depression. Hebei Med J 2010;32:3185-3186.

82. Zhang PZ. Jin Xiang Shu Gan pills for the treatment of depression (Liver Qi stagnation and Spleen deficiency syndrome): A randomised double-blind, multicenter parallel study. World Clin Drugs 2014;35: 399-403.

83. Zhang Y. Clinical Study of Bu Shen Shu Gan Hua Yu Formula for the Treatment of Depression During Menopause. Beijing: Beijing University of Chinese Medicine, 2013.

84. Zhang ZQ. A Randomised Controlled Study of Yu Le Shu Formula for Depression with the Liver Stagnation Transforming Into Fire Syndrome. Chengdu: Chengdu University of Chinese Medicine, 2009.

85. Zhao HM, Jiang H, Pang TL. Chai Gui Kai Yu Tang for the treatment of depression patients with the Liver stagnation and phlegm stagnation syndrome-38 cases. Hebei Chin Med 2016;38:209-211.

86. Zhao XP, Lin H. Fluoxetine combined with Chai Hu Shu Gan San modified for the treatment of postpartum depression. Liaoning J Tradit Chin Med 2006;33:586-587.

87. Zhong L. Clinical observation of Kai Yu Ning Shen Tang for the treatment of depression. Guang Ming Chin Med 2013;28:931-932.

88. Zhong XY, Li QQ, Liao XN. 50 cases of Chai Hu combined with Modified Long Gu Mu Li Tang for depression. China Health Care Nutr 2012;11:4746-4747.

89. Zhou B, Yan H. Integration of Chinese medicine and western medicine for the treatment of deprssion-30 cases. Tianjin J Tradit Chin Med 2012;29:329-331.

90. Zhou J. Modified Xiao Yao Capsules for the Treatment of Mild to Moderate Depression with the Liver Qi Stagnation Transformed to Fire Syndrome: A Multi-Center Randomised Controlled Trial. Beijing: China Academy of Chinese Medical Sciences, 2013.

91. Zhou MY. Shu Gan Jie Yu Tang combined with Citalopram for the treatment of depression- 40 cases. Tradit Chin Med Res 2012;25:33-34. 
92. Zhu JP. Observation on the effect of modified Suan Zao Ren Tang for the treatment of postpartum depression. J N Chin Med 2014;46:105-106.

93. Zong CC. Clinical Study of Yi Shen Qing Xin Tang on the Treatment of Depression. Jinan: Shandong University of Chinese Medicine, 2014.

94. Kennedy SH, Lam RW, McIntyre RS, et al. Canadian Network for Mood and Anxiety Treatments (CANMAT) 2016 Clinical Guidelines for the Management of Adults with Major Depressive Disorder: Section 3. Pharmacological Treatments. Can J Psychiatry 2016;61:540-560.

95. Jun JH, Choi TY, Lee JA, et al. Herbal medicine (Gan Mai Da Zao decoction) for depression: A systematic review and meta-analysis of randomized controlled trials. Maturitas 2014;79:370-380.

96. Ren Y, Zhu C, Wu J, et al. Comparison between herbal medicine and fluoxetine for depression: A systematic review of randomized controlled trials. Complement Ther Med 2015;23:674-684.

97. Yeung WF, Chung KF, Ng KY, et al. A systematic review on the efficacy, safety and types of Chinese herbal medicine for depression. J Psychiatr Res 2014;57:165175.

98. Zhao H, Wan X, Chen JX. A mini review of traditional Chinese medicine for the treatment of depression in China. Am J Chin Med 2009;37:207-213.

99. Cipriani A, Furukawa TA, Salanti G, et al. Comparative efficacy and acceptability of 21 antidepressant drugs for the acute treatment of adults with major depressive disorder: A systematic review and network meta-analysis. Lancet 2018;391:1357-1366.

100. Cipriani A, Furukawa TA, Salanti G, et al. Comparative efficacy and acceptability of 12 new-generation antidepressants: A multiple-treatments meta-analysis. Lancet 2009;373:746-758.

101. Bauer M, Severus E, Moller HJ, Young AH. Pharmacological treatment of unipolar depressive disorders: Summary of WFSBP guidelines. Int J Psychiatry Clin Pract 2017;21:166-176.

102. Liu J, Fang Y, Yang L, et al. A qualitative, and quantitative determination and pharmacokinetic study of four polyacetylenes from Radix Bupleuri by UPLC-PDA-MS. J Pharm Biomed Anal 2015;111:257-265.

103. Wang Y, Gao SM, Li R, et al. Antidepressant-like effects of the Radix Bupleuri and Radix Paeoniae Alba drug pair. Neurosci Lett 2016;633:14-20.
104. Liu X, Zheng X, Du G, et al. Brain metabonomics study of the antidepressant-like effect of Xiaoyaosan on the CUMS-depression rats by $\mathrm{H}$ NMR analysis. J Ethnopharmacol 2019;235:141-154.

105. Li YH, Zhang CH, Qiu J, et al. Antidepressant-like effects of Chaihu-Shugan-San via SAPK/JNK signal transduction in rat models of depression. Pharmacogn Mag 2014;10: 271-277.

106. Qiu J, Hu SY, Zhang CH, et al. The effect of ChaihuShugan-San and its components on the expression of ERK5 in the hippocampus of depressed rats. J Ethnopharmacol 2014;152:320-326.

107. Schulz KF, Altman DG, Moher D. CONSORT 2010 statement: Updated guidelines for reporting parallel group randomised trials. BMJ 2010;340:c332.

108. Gagnier JJ, Boon H, Rochon P, et al. Reporting randomized, controlled trials of herbal interventions: An elaborated CONSORT statement. Ann Intern Med 2006;144: 364-367.

109. Bian Z, Liu B, Moher D, et al. Consolidated standards of reporting trials (CONSORT) for traditional Chinese medicine: Current situation and future development. Front Med 2011;5:171-177.

Address correspondence to: Yan $\mathrm{Li}, \mathrm{PhD}$

Department of Psychology and Sleep Medicine Guangdong Provincial Hospital of Traditional Chinese Medicine

111 Dade Road Yuexiu District Guangzhou 510120 P.R. China

E-mail: janeliyan2018@163.com

Charlie Changli Xue, PhD The China-Australia International Research Centre for Chinese Medicine School of Health and Biomedical Sciences RMIT University

PO BOX 71

Bundoora, VIC 3083

Australia

E-mail: charlie.xue@rmit.edu.au 